\title{
What Demographic and Clinical Characteristics Correlate With Expectations With Trapeziometacarpal Arthritis?
}

\author{
Lana Kang MD, MSc, Joseph Nguyen MPH, Sohaib Z. Hashmi MD, \\ Steve K. Lee MD, Andrew J. Weiland MD, Carol A. Mancuso MD
}

Received: 27 January 2017/Accepted: 13 April 2017/Published online: 19 April 2017

(C) The Association of Bone and Joint Surgeons (B) 2017

\begin{abstract}
Background Pretreatment variables have been shown to be associated with the fulfillment of patient expectations, yet in treating thumb trapeziometacarpal osteoarthritis (OA) it remains unclear how patient expectations correlate with the effectiveness of treatment. An increased understanding of the variables that affect patient expectations enables tailored patient education and patient-provider communication.

Questions/purposes (1) Is there a correlation between patient demographics and clinical characteristics, and the

Each author certifies that neither he or she, nor any member of his or her immediate family, have funding or commercial associations (consultancies, stock ownership, equity interest, patent/licensing arrangements, etc) that might pose a conflict of interest in connection with the submitted article.

All ICMJE Conflict of Interest Forms for authors and Clinical Orthopaedics and Related Research ${ }^{\circledR}$ editors and board members are on file with the publication and can be viewed on request.

Each author certifies that his or her institution approved the human protocol for this investigation, that all investigations were conducted in conformity with ethical principles of research, and that informed consent for participation in the study was obtained.

This work was performed at the Hospital for Special Surgery, New York, NY, USA.
\end{abstract}

Electronic supplementary material The online version of this article (doi:10.1007/s11999-017-5359-9) contains supplementary material, which is available to authorized users.

\section{S. Z. Hashmi}

Department of Orthopaedic Surgery, Northwestern University, Chicago, IL, USA

L. Kang ( $₫)$, J. Nguyen, S. K. Lee, A. J. Weiland,

C. A. Mancuso

Hospital for Special Surgery, 535 E 70th Street, New York, NY 10021, USA

e-mail: kangl@hss.edu expectations the patients have when seeking treatment for trapeziometacarpal OA? (2) What factors are independently associated with the total expectations score and frequency of expecting "back to normal" among patients treated for trapeziometacarpal OA?

Methods Between March 2011 and October 2013, 89 patients of all 96 eligible patients seeking treatment for trapeziometacarpal OA were approached and agreed to participate in this study. Participants completed a validated expectations survey measuring the number of expectations and the degree of improvement expected. Comparative analysis of demographic and clinical characteristics and multivariate regression analysis against patients' expectations were performed to assess and identify factors that correlate with the number and degree of expectations. Sample size was determined with an a priori power analysis (with $80 \%$ power and statistical significance set at $\mathrm{p}<0.05$ ), which showed that 88 patients were needed to detect the minimal clinical difference of 12 points in the Michigan Hand Questionnaire; we then increased this by $10 \%$ to allow for potential dropouts.

Results After controlling for potential confounding variables such as age, hand dominance, and work status, the following factors were associated with a higher expectations score: choice of surgery $(\beta=11.5$; $95 \% \mathrm{CI}, 0.7-$ $23.8 ; p=0.044)$, female gender $(\beta=19.0 ; 95 \%$ CI, $5.3-$ $32.7 ; \mathrm{p}=0.007)$, and dominant side affected $(\beta=-41.6$; $95 \% \mathrm{CI},-63.7$ to $-19.5 ; \mathrm{p}<0.001)$. For the frequency of "back to normal" responses, surgical treatment $(\beta=7.4$; 95\% CI, 2.3-12.4; $\mathrm{p}=0.005)$ and history of previous injury $(\beta=8.2 ; 95 \% \quad C I, 0.1-16.3 ; p=0.047)$ were independently associated factors after controlling for confounding variables. There were no independent associations with age, marital status, work status, depression or anxiety, or prior contralateral surgery. 
Conclusions Patients whose dominant side was affected, were female, and chose surgical treatment, had higher total expectations. Patients who reported an antecedent injury and chose surgical treatment more frequently expected a return to normal. With identification of these factors, orthopaedic surgeons can recognize patients who are prone to higher expectations, and, thus, have the opportunity to implement efficient pretreatment education. In addition, identification of specific factors enables a focused measure of the effect of these factors on the fulfillment of expectations.

Level of Evidence Level II, prognostic study.

\section{Introduction}

As patient perspectives and patient satisfaction have become major components of assessing outcomes, so have patient expectations $[1,7,10,11,13]$. Patient expectations may be the cumulative result of the patient's generalized knowledge of treatment, prior experiences of self and others, and information derived from today's different forms of communication and data access. Understanding independent variables that may affect expectations is relevant in our evolving healthcare system because aligning patients' expectations with goals the physician believes are reasonable may foster patient-provider collaboration and increase patient satisfaction [11, 13-18, 21, 32-34]. Patients seek treatment for trapeziometacarpal osteoarthritis (OA) to alleviate pain and improve function [9, 12, 37, 39]. The degree of dysfunction prompting patients to seek medical evaluation does not necessarily correlate with radiographic staging of arthritis [9, 12, 37], yet may affect patients' expectations when seeking treatment. Factors such as symptom tolerance, personal preferences, aversion to surgery, and surgeon recommendations may potentially influence the quality and number of expectations that patients have after deciding on choice of treatment.

With the current healthcare climate requiring proof of patient-centered care $[31,33,35,38,42,43]$, efforts to understand and meet patient expectations potentially carry greater impact than currently used objective metrics. Because the ability of our profession to measure the quality and effectiveness of treatment is an evolving and imperfect science, identifying the factors associated with a spectrum of patient expectations allows providers to recognize patients whose pretreatment characteristics may be asynchronous with the projected treatment results.

To this end, we asked: (1) Is there a correlation between patient demographics and clinical characteristics, and the expectations the patients have when seeking treatment for trapeziometacarpal OA? (2) What factors are independently associated with the total expectations score and frequency of expecting "back to normal" among patients treated for trapeziometacarpal OA?

\section{Patients and Methods}

This study included a cohort of adult-aged patients who were recruited during a 2-year period (March 2, 2013, through April 1, 2015) from the practices of four hand surgeons (LK, SKL, AJW, EAA) at a single institution. Patients seeking treatment for trapeziometacarpal OA, which was the primary diagnosis, were included. Patients were administered a survey that has been validated to measure the number of expectations and the degree of improvement expected [20]. This study was approved by the institutional review board.

Patients who were adult-aged and English-speaking were eligible for this study if trapeziometacarpal OA was the primary condition diagnosed by the participating hand surgeon investigator.

From March 2011 to October 2013, 89 of the 96 patients who fulfilled eligibility criteria and were approached, volunteered their participation, and successfully completed the expectations survey, were included in the study. Patients were excluded if they did not speak English, were unable to provide informed consent, had another condition that affected use of the thumb (such as trigger thumb, de Quervain's, carpal tunnel syndrome, or thumb metacarpophalangeal OA) to which the trapeziometacarpal arthritic condition was considered by the patient to be secondary, had received any treatment within 90 days of the time of the interview provided by a licensed healthcare provider, or chose not to participate. Seven of the 96 eligible patients were excluded because they did not complete the expectations survey, and none who were approached were excluded for reasons attributable to the criteria listed above.

All patients provided informed consent for study participation. Diagnosis was based on clinical information including patient's history and symptomatology, physical examination, and plain radiographs. All participants completed the survey within 1 month before receiving treatment. The desired treatment included injection of cortisone versus thumb trapeziometacarpal arthroplasty. All of the expectations surveys were administered and completed in person or by telephone communication before the patients received any subsequent treatment.

All 89 patients who fulfilled eligibility criteria were included in this study. They had an average age of 65 years (range, 40-89 years) (Table 1). Eighty (88\%) chose 
Table 1. Patient demographics and clinical characteristics

\begin{tabular}{|c|c|c|c|}
\hline Demographic & $\begin{array}{l}\text { Total } \\
\text { number } \\
\text { assessed }\end{array}$ & Number & $\begin{array}{l}\text { SD (range) } \\
\text { or percentage }\end{array}$ \\
\hline Average age (years) & 89 & 65 & $10.6(40-89)$ \\
\hline Gender & 89 & & \\
\hline Male & & 16 & $18 \%$ \\
\hline Female & & 73 & $82 \%$ \\
\hline Marital status & 82 & & \\
\hline Not married & & 27 & $33 \%$ \\
\hline Married & & 55 & $67 \%$ \\
\hline Working status & 80 & & \\
\hline $\begin{array}{l}\text { Inactive (retired/ } \\
\text { unemployed) }\end{array}$ & & 34 & $43 \%$ \\
\hline Active & & 46 & $57 \%$ \\
\hline Hand dominance & 82 & & \\
\hline Right & & 74 & $90 \%$ \\
\hline Left & & 8 & $10 \%$ \\
\hline $\begin{array}{l}\text { Laterality of the affected } \\
\text { hand(s) }\end{array}$ & 80 & & \\
\hline Right & & 43 & $54 \%$ \\
\hline Left & & 21 & $26 \%$ \\
\hline Bilateral & & 16 & $20 \%$ \\
\hline Dominant hand affected? & 64 & & \\
\hline Yes & & 41 & $64 \%$ \\
\hline No & & 23 & $36 \%$ \\
\hline Antecedent injury? & 80 & & \\
\hline Yes & & 5 & $6 \%$ \\
\hline No & & 75 & $94 \%$ \\
\hline \multicolumn{4}{|l|}{$\begin{array}{l}\text { History of depression or } \\
\text { anxiety? }\end{array}$} \\
\hline Yes & 81 & 73 & $90 \%$ \\
\hline No & & 8 & $10 \%$ \\
\hline Contralateral TMC surgery? & 54 & & \\
\hline Yes & & 4 & $7 \%$ \\
\hline No & & 50 & $93 \%$ \\
\hline
\end{tabular}

$\mathrm{TMC}=$ trapeziometacarpal.

injection, and $16(72 \%)$ chose surgery. The majority were women (73 [82\%] women and 16 [18\%] men). More patients were married (55 married and 27 single, widowed, or living along), and more patients were actively working (46 [58\%]) compared with those who were retired or currently not actively employed (34 [43\%]). The majority reported that they were right-hand-dominant (74 [90\%]) compared with those who were left-hand-dominant (eight [10\%]). Six percent of the patients had their dominant side as the affected side. Of the patient self-reported comorbidities, eight patients (10\%) reported anxiety or depression. A bivariate analysis of the included patients revealed that those with a status of being retired or inactive and a history of an antecedent injury were associated with an increased frequency of expecting 'back to normal' and that the choice of surgery was associated with a higher total expectations score and frequency of expecting 'back to normal' (Table 2).

Data were based on information recorded before the provision of treatment. Treatment options that were offered included either an injection of cortisone (with triamcinolone or betamethasone) or thumb trapeziometacarpal joint arthroplasty (involving trapeziectomy with or without ligament reconstruction and/or suspensionplasty and without any other additional procedures).

\section{Patient Demographics and Clinical Characteristics}

The following demographic information was recorded: age, gender, hand dominance, marital status, laterality of the trapeziometacarpal OA condition, and work status (an active work status versus an inactive work status from being retired or unemployed such as for family care or from an unrelated disability). These variables were chosen because the history-taking of patients with hand conditions typically elicits this information. The following clinical characteristics were recorded: a patient-reported antecedent injury (described as a minor strain, an overuse event, or other nonimpact mechanism) marking the onset of symptoms, a history of contralateral thumb trapeziometacarpal arthroplasty for the same diagnosis, and the patient's preferred choice of treatment. These variables were chosen based on the frequently cited words and concepts that were recorded during the patient interviews needed to compose the expectations survey [20]. Owing to a growing body of research suggesting a role of depression and anxiety in the management of patients with many hand conditions [8, 41, 42], an additional variable included in the multivariate regression model was a self-reported history of depression and anxiety.

\section{Thumb/Hand Arthritis Expectations Survey}

This study used a 19-item validated expectations survey specific to trapeziometacarpal OA [13]. This survey was developed using standard qualitative techniques of an iterative process of coding patients' words, which were recorded verbatim from open-ended responses [4, 20, 36]. The survey was prefaced by the following question: "For each of the following, what do you expect after treatment for your hand arthritis?" with response options of "back to normal," "a lot of improvement," "a moderate amount of improvement," "a little improvement", or "I do not have this expectation or this expectation does not apply to me" 
Table 2. Bivariate analysis of demographics and clinical characteristics

\begin{tabular}{|c|c|c|c|c|}
\hline Demographic variable and clinical characteristic & $\begin{array}{l}\text { Mean total expectations } \\
\text { score (SD) }\end{array}$ & $\mathrm{p}$ Value & $\begin{array}{l}\text { Mean frequency of expecting } \\
\text { 'back to normal' }\end{array}$ & $\mathrm{p}$ Value \\
\hline \multicolumn{5}{|l|}{ Treatment } \\
\hline Injection & $73.04(20.43)$ & \multirow[t]{2}{*}{$<0.001$} & $4.99(6.53)$ & \multirow[t]{2}{*}{$<0.001$} \\
\hline Surgery & $90.98(11.17)$ & & $11.31(5.30)$ & \\
\hline \multicolumn{5}{|l|}{ Gender } \\
\hline Male & $72.95(21.02)$ & \multirow[t]{2}{*}{0.473} & $5.81(6.61)$ & \multirow[t]{2}{*}{0.840} \\
\hline Female & $76.99(20.17)$ & & $6.19(6.83)$ & \\
\hline \multicolumn{5}{|l|}{ Marital status } \\
\hline Not married & $76.09(21.05)$ & \multirow[t]{2}{*}{0.840} & $6.78(7.36)$ & \multirow[t]{2}{*}{0.339} \\
\hline Characteristic & $75.11(20.26)$ & & $5.27(6.30)$ & \\
\hline \multicolumn{5}{|l|}{ Working status } \\
\hline Inactive/retired & $79.38(21.52)$ & \multirow[t]{2}{*}{0.170} & $7.50(6.93)$ & \multirow[t]{2}{*}{0.047} \\
\hline Active & $73.02(19.42)$ & & $4.61(6.36)$ & \\
\hline \multicolumn{5}{|l|}{ Hand dominance } \\
\hline Right & $75.86(20.88)$ & \multirow[t]{2}{*}{0.581} & $6.05(6.80)$ & \multirow[t]{2}{*}{0.240} \\
\hline Left & $71.63(16.10)$ & & $3.13(4.70)$ & \\
\hline \multicolumn{5}{|l|}{ Dominant hand affected? } \\
\hline No & $80.43(21.26)$ & \multirow[t]{2}{*}{0.462} & $7.65(6.96)$ & \multirow[t]{2}{*}{0.316} \\
\hline Yes & $76.46(20.23)$ & & $5.85(6.76)$ & \\
\hline \multicolumn{5}{|l|}{ Antecedent injury? } \\
\hline No & $75.33(20.11)$ & \multirow[t]{2}{*}{0.196} & $5.52(6.51)$ & \multirow[t]{2}{*}{0.041} \\
\hline Yes & $87.47(21.34)$ & & $11.80(7.16)$ & \\
\hline \multicolumn{5}{|l|}{ Contralateral TMC surgery? } \\
\hline No & $73.60(19.21)$ & \multirow[t]{2}{*}{0.720} & $4.75(9.50)$ & \multirow[t]{2}{*}{0.891} \\
\hline Yes & $69.97(22.89)$ & & $4.32(5.75)$ & \\
\hline \multicolumn{5}{|l|}{ Depression or anxiety } \\
\hline No & $76.09(20.75)$ & \multirow[t]{2}{*}{.0750} & $6.20(6.88)$ & \multirow[t]{2}{*}{0.745} \\
\hline Yes & $78.04(15.45)$ & & $5.38(5.66)$ & \\
\hline
\end{tabular}

$* \mathrm{p}<0.05=$ statistically significant $; \mathrm{TMC}=$ trapeziometacarpal.

(Appendix 1. Supplemental material is available with the online version of $C O R R^{\circledR}$.).

This expectations survey provided a score that indicated the number of expectations and degree of expectations and, thereby, measured patient expectations according to the number of discrete expectations and the degree to which each of these is expected. The degree of expecting improvement was reflected by the frequency that each subject chose the categorical response "back to normal," which indicates higher ranking of the severity of the expectations and ranged from zero to 19 . The number of expectations was reflected by the total expectations score, which is a summation of the expectations of all the items of the survey. This total expectations score then was calculated as follows: 4 points are assigned for the response of "complete improvement" or "back to normal," and points for each subsequent response are assigned in descending order to a minimum of zero points for the response "I do not have this expectation or this expectation does not apply to me." The maximum number of items that applies to any patient is 19. The overall score is obtained by summing all responses, dividing by the maximum possible score $(4 \cdot 19=76)$, and normalizing to 100 (Appendix 2. Supplemental material is available with the online version of $C O R R^{\circledR}$.). Therefore, the possible scores range from 0 to 100 with a higher score indicating greater expectations.

\section{Statistical Analysis}

Patient demographics and clinical characteristics were measured against the total expectations score and the frequency of expecting improvement back to normal. Overall summary statistics were calculated in terms of means and SDs for continuous variables, and frequencies and percentages were calculated for discrete variables. To analyze 
Table 3. Multivariate regression models for total expectations score

\begin{tabular}{|c|c|c|c|c|}
\hline Variable & $\beta$-coefficient & Standard error & $(95 \% \mathrm{CI})$ & $\mathrm{p}$ Value \\
\hline (Constant) & 81.2 & 11.7 & $(57.6-104.8)$ & 0.000 \\
\hline Surgery (versus injection)* & 11.5 & 6.1 & $(0.7-23.8)$ & 0.044 \\
\hline Age* & - & - & - & - \\
\hline Female (versus male) & 19.0 & 6.8 & $(5.3-32.7)$ & 0.007 \\
\hline Married (versus not married)* & - & - & - & - \\
\hline Active work status (versus inactive/retired)* & - & - & - & - \\
\hline Dominant side affected? & -41.6 & 11.0 & $(-63.7$ to -19.5$)$ & 0.000 \\
\hline Preceding injury* & - & - & - & - \\
\hline Prior contralateral surgery* & - & - & - & - \\
\hline Depression or anxiety* & - & - & - & - \\
\hline
\end{tabular}

the independent associations between demographic and clinical characteristics and expectations, independent samples t-tests and chi-square tests were performed for normally distributed data, and Mann-Whitney U tests were performed for nonparametric continuous variables. Fisher's exact tests were performed for discrete variables that had $80 \%$ of an expected count less than five. Sample size was determined with a power analysis (with $80 \%$ power and statistical significance set at $\mathrm{p}<0.05$ ) that showed that 88 patients were needed to detect the minimal clinical difference of 12 points in the Michigan Hand Outcomes Questionnaire (used as the validated tool of reference; http://mhq.lab.medicine.umich.edu/) between patients who were above versus below the overall mean of the expectations survey. The study was designed to be conservative with an additional $10 \%$ increase in sample size enrollment for a total sample size of 96 patients to account for potential patients who decided to no longer be part of the study or were missing data.

After the analysis of inferential statistics, all of the above-described demographic and clinical characteristics chosen for analysis were considered eligible variables in the multivariable regression analysis of independent associations. Regression models were analyzed using a pairwise deletion method (available case analysis) to maximize the data collected from the study cohort and to account for missing data. Because of the exploratory nature of the analysis, a critical $p$ value of 0.15 was used as the threshold for retention in the final model following a stepwise procedure of the regression analysis. Variables that were dropped from the final models were considered as variables not associated with the outcomes assessed. Variables that achieved a probability of 0.05 or less were considered statistically significant factors in the final model. For all regression models, $\beta$ coefficients were reported to estimate the magnitude of the effect with their respective $95 \%$ CIs for estimates of precision. All analyses were performed using SPSS Version 20.0 (IBM Corp, Armonk, NY, USA) [2].

\section{Results}

In the regression model analysis for the outcome of a higher total expectations score (Table 3), the following patient variables and clinical characteristics were found to be an independently associated patient factor after controlling for the other potential confounders such as age, hand dominance, and work status: choice of surgery ( $\beta=11.5 ; 95 \%$ CI, 0.7-23.8; $p=0.044)$, female gender ( $\beta=19.0 ; 95 \%$ CI, 5.3-32.7; $\mathrm{p}=0.007)$, and dominant side affected $(\beta=-41.6 ; 95 \% \mathrm{CI},-63.7$ to -19.5 ; $\mathrm{p}<0.001$ ).

For the outcome of an increased frequency of "back to normal" responses (Table 4), surgical treatment was an independent factor $(\beta=5.6 ; 95 \% \quad C I, \quad 0.2-11.0$; $p=0.043$ ), and previous injury also was found to be an independent factor with respect to frequency of "back to normal responses" after controlling for potentially confounding variables $(\beta=8.1 ; 95 \% \quad \mathrm{CI}, \quad 0.1-16.3$; $\mathrm{p}=0.050$ ).

\section{Discussion}

Orienting care toward achieving explicit metrics associated with patient satisfaction is a contemporary priority $[10,11]$. Understanding the variables that affect expectations-and 
Table 4. Multivariate regression models for frequency of back to normal responses

\begin{tabular}{|c|c|c|c|c|}
\hline Variable & $\beta$-coefficient & Standard error & $95 \% \mathrm{CI}$ & $\mathrm{p}$ value \\
\hline (Constant) & 4.0 & 1.0 & $1.9-6.1$ & 0.000 \\
\hline Surgery (versus injection)* & 5.6 & 2.7 & $0.2-11.0$ & 0.043 \\
\hline Age* & - & - & - & - \\
\hline Female (versus male)* & - & - & - & - \\
\hline Married (versus not married)* & - & - & - & - \\
\hline Active work status (versus inactive/retired)* & - & - & - & - \\
\hline Affected hand* & - & - & - & - \\
\hline Dominant side affected?* & - & - & - & - \\
\hline Preceding injury & 8.1 & 4.0 & $0.1-16.3$ & 0.050 \\
\hline Prior contralateral surgery* & - & - & - & - \\
\hline Depression or anxiety* & - & - & - & - \\
\hline
\end{tabular}

$R^{2}=0.280 ;-=$ did not meet the threshold for retention in the final model; $*=$ these variables without any numeric values are those that attained $\mathrm{p}$ values greater than our threshold, ultimately were deleted from the model, and were considered not predictive of each model's outcome. The final variables listed with numeric values were those that had attained a p value within our threshold for retention in the final model.

so drive satisfaction-is critical to achieving these goals $[32-34,38]$. We evaluated these factors in the context of trapeziometacarpal OA.

There are several study limitations. First, the study design was cross sectional and, therefore, fails to reflect time-related changes or associations. Second, the dataset was not complete for several categories, with at most $10 \%$ of the 89 total patients missing data for categories for which associations were observed. However, our study was conservative in design, anticipating that a portion of participants who might enroll and then later drop out or would be missing data. In addition, regression models were analyzed using a pairwise deletion method (available case analysis) to maximize the data collected from the study cohort and to account for missing data. Third, the study subjects included patients from an urban setting seeking care at a tertiary care orthopaedic institution; therefore, their demographic and clinical characteristics may not fully represent other patient populations. There were numerous variables that were not evenly distributed among the patient population. As a result, a post hoc power analysis indicates that the study was underpowered to detect differences in the expectations outcomes among the factors assessed. However, the post hoc power analysis did show that the given sample size of our study was more than $90 \%$ powered to detect the differences that were found between patients who underwent surgery and those who chose to have injections. Our final regression models were limited to the elements of data that were available in our patient database. Other characteristics not collected in our study may have the potential to influence our findings and also could improve our $\mathrm{R}^{2}$ values to explain the variability of our outcomes.
We found a correlation between certain demographic and clinical characteristics and patient expectations before receiving treatment of trapeziometacarpal OA. While the effect of patient expectations and satisfaction in other areas of medicine has been studied for several decades [16-18, 21, 28, 33, 38, 40, 43], efforts in the field of orthopaedics and specifically in orthopaedic hand surgery have opened doors to improved understanding of factors that potentially affect patient expectations [3-6, 8, 10, 11, 13-15, 19, 29, 30, 42]. Extensive investigation of condition-specific expectations has shown that patient expectations do not come as one-size fits all [22-28, 30, 31]. Different from decades ago is that in today's current healthcare climate, the provision of care is becoming increasingly contingent on 'merit-based measures'. The difficulty with this principle in the field of hand surgery is that most problematic hand conditions occur with relative infrequency such that this renders observational and objectively derived data hardly qualifiable as behavior-changing evidence. To address the need to better understand condition-specific patient expectations, this study was developed premised on the principle that an identification of the factors that affect patient expectations associated with trapeziometacarpal OA potentially enables providers to explore whether patients with characteristics associated with higher expectations also have realistic expectations, and if so, whether the offered treatment will meet their perceived expectations.

This study also identified specific patient factors, namely, a history of antecedent trauma, the choice of surgical treatment, female gender, and dominant-hand affected, to be associated with pretreatment patient expectations. We believe these results complement prior 
studies that have analyzed variables that affect the satisfaction of patients having hand surgery $[1,3,5,7,8,14,20$, $29,30,32,41,42]$. We believe our study is distinct from prior studies because it applied a survey that was developed specifically in the context of orthopaedic hand surgery, rather than applying a survey developed in the context of other medical and psychologic fields of study. The expectations survey is a validated survey developed from patient-volunteered content, was disease specific, and has been shown to be reliable, reproducible, and clinically relevant [20]. With use of this study, orthopaedic surgeons treating trapeziometacarpal $\mathrm{OA}$ have the opportunity to ensure that specific pretreatment expectations are congruent with the goals of the treating team. Identification of the independent factors, as found by our analysis, can be used by surgeons to identify patients who may have higher expectations before undergoing treatment. Finding that a history of an antecedent trauma, female gender, hand dominance, and choice of surgical treatment with our expectations survey renders use of these factors as variables to determine whether and to what degree the fulfillment of expectations after receiving treatment for trapeziometacarpal OA has been achieved. In other words, these factors can be used further to compare patients' expected pretreatment improvement with the posttreatment improvement attained, with the magnitude of change as a measure of the fulfillment of expectations. We believe that assessing this fulfillment of expectations as a function of demographic, psychosocial, and clinical characteristics will be essential to identify and overcome barriers to communication, and thereby, increase patient satisfaction.

This study shows that a correlation between demographic and clinical characteristics of patients with trapeziometacarpal $\mathrm{OA}$ and expectations of treatment exists. The identification of a history of antecedent trauma, female gender, hand dominance, and choice of surgical treatment, as found by our analysis, can be used by surgeons to overcome barriers of communication by identifying patients who may have higher expectations before undergoing treatment. Recognizing these correlations, orthopaedic surgeons treating trapeziometacarpal OA have the opportunity to explore and ensure that specific pretreatment expectations are congruent with the goals of the treating team. In addition, these identified factors can be used in a comparative analysis between patients' expected pretreatment improvement and the posttreatment improvement attained, with the magnitude of change as a measure of fulfillment of expectations. We believe that assessing this fulfillment of expectations as a function of demographic, psychosocial, and clinical characteristics will be essential to build a system that provides orthopaedic expertise focused on patient-centered care and patient satisfaction.
Acknowledgments We thank Edward A. Athanasian MD (Department of Orthopaedic Surgery, Hospital for Special Surgery and Weill Cornell Medical College, New York, NY) who contributed to the recruitment of patients for this study.

\section{References}

1. Abtahi AM, Presson AP, Zhang C, Saltzman CL, Tyser AR. Association between orthopaedic outpatient satisfaction and nonmodifiable patient factors. J Bone Joint Surg Am. 2015;97:10411048.

2. Armitage P, Berry B. Statistical Methods in Medical Research. 3rd ed. Malden, MA: Blackwell Science Inc; 1994.

3. Becker SJ, Makanji HS, Ring D. Expected and actual Improvement of symptoms with carpal tunnel release. J Hand Surg Am. 2012;37:1324-1329.

4. Berkwits M, Inui TS. Making use of qualitative research techniques. J Gen Intern Med. 1998;13:195-199.

5. Bogoch ER, Escott BG, Ronald K. Hand appearance as a patient motivation for surgery and a determinant of satisfaction with metacarpophalangeal joint arthroplasty for rheumatoid arthritis. $J$ Hand Surg Am. 2011;36:1007-1014.

6. Bot AG, Becker SJ, van Dijk CN, Ring D, Vranceanu AM. Abbreviated psychologic questionnaires are valid in patients with hand conditions. Clin Orthop Relat Res. 2013;471:4037-4044.

7. Bot AG, Bossen JK, Herndon JH, Ruchelsman DE, Ring D, Vranceanu AM. Informed shared decision-making and patient satisfaction. Psychosomatics. 2014;55:586-594.

8. Briet JP, Hageman MG, Overbeek CL, Mudgal C, Ring DC, Vranceanu AM. Factors associated with met expectations in patients with hand and upper extremity disorders: a pilot study. Psychosomatics. 2016;57:401-408.

9. Brown GD 3rd, Roh MS, Strauch RJ, Rosenwasser MP, Ateshian GA, Mow VC. Radiography and visual pathology of the osteoarthritic scaphotrapezio-trapezoidal joint, and its relationship to trapeziometacarpal osteoarthritis. J Hand Surg Am. 2003;28:739-743.

10. Chow A, Mayer EK, Darzi AW, Athanasiou T. Patient-reported outcome measures: the importance of patient satisfaction in surgery. Surgery. 2009;146:435-443.

11. Ford EW, Huerta TR, Diana ML, Kazley AS, Menachemi N. Patient satisfaction scores and their relationship to hospital website quality measures. Health Mark Q. 2013;30:334-348.

12. Glickel SZ. Clinical assessment of the thumb trapeziometacarpal joint. Hand Clin. 2001;17:185-195.

13. Graham B, Green A, James M, Katz J, Swiontkowski M. Measuring patient satisfaction in orthopaedic surgery. J Bone Joint Surg Am. 2015;97:80-84.

14. Hageman MG, Briët JP, Bossen JK, Blok RD, Ring DC, Vranceanu AM. Do previsit expectations correlate with satisfaction of new patients presenting for evaluation with an orthopaedic surgical practice? Clin Orthop Relat Res. 2015;473:716-721.

15. Hageman MG, Briet JP, Oosterhoff TC, Bot AG, Ring D, Vranceanu AM. The correlation of cognitive flexibility with pain intensity and magnitude of disability in upper extremity illness. $J$ Hand Microsurg. 2014;6:59-64.

16. Jackson JL, Chamberlin J, Kroenke K. Predictors of patient satisfaction. Soc Sci Med. 2001;52:609-620.

17. Jackson JL, Kroenke K. Difficult patient encounters in the ambulatory clinic: clinical predictors and outcomes. Arch Intern Med. 1999;159:1069-1075.

18. Jackson JL, Kroenke K. The effect of unmet expectations among adults presenting with physical symptoms. Ann Intern Med. 2001;134(9 pt 2):889-897. 
19. Kadzielski J, Malhotra LR, Zurakowski D, Lee SG, Jupiter JB, Ring D. Evaluation of preoperative expectations and patient satisfaction after carpal tunnel release. J Hand Surg Am. 2008;33:1783-1788.

20. Kang L, Hashmi SZ, Nguyen J, Lee SK, Weiland AJ, Mancuso CA. Patients with thumb carpometacarpal arthritis have quantifiable characteristic expectations that can be measured with a survey. Clin Orthop Relat Res. 2016;474:213-221.

21. Lutz GK, Butzlaff ME, Atlas SJ, Keller RB, Singer DE, Devo RA. The relation between expectations and outcomes in surgery for sciatica. J Gen Intern Med. 1999;14:740-744.

22. Mancuso CA, Altchek DW, Craig EV, Jones EC, Robbins L, Warren RF, Williams-Russo P. Patients' expectations of shoulder surgery. J Shoulder Elbow Surg. 2002;11:541-549.

23. Mancuso CA, Cammisa FP, Sama AA, Hughes AP, Ghomrawi HM, Girardi FP. Development and testing of an expectations survey for patients undergoing lumbar spine surgery. J Bone Joint Surg Am. 2013;95:1793-1800.

24. Mancuso CA, Jout J, Salvati EA, Sculco TP. Fulfillment of patients' expectations for total hip arthroplasty. J Bone Joint Surg Am. 2009;91:2073-2078.

25. Mancuso CA, Salvati EA, Johanson NA, Peterson MG, Charlson ME. Patients' expectations and satisfaction with total hip arthroplasty. J Arthroplasty. 1997;12:387-396.

26. Mancuso CA, Sculco TP, Salvati EA. Patients with poor preoperative functional status have high expectations of total hip arthroplasty. J Arthroplasty. 2003;18:872-878.

27. Mancuso CA, Sculco TP, Wickiewicz TL, Jones EC, Robbins L, Warren RF, Williams-Russo P. Patients' expectations of knee surgery. J Bone Joint Surg Am. 2001;83:1005-1012.

28. Mandl LA, Galvin DH, Bosch JP, George CC, Simmons BP, Axt TS, Fossel AH, Katz JN. Metacarpophalangeal arthroplasty in rheumatoid arthritis: what determines satisfaction with surgery? $J$ Rheumatol. 2002;29:2488-2491.

29. Menendez ME, van Hoorn BT, Mackert M, Donovan EE, Chen NC, Ring D. Patients with limited health literacy ask fewer questions during office visits with hand surgeons. Clin Orthop Relat Res. 2017;475:1291-1297.

30. Noble PC, Conditt MA, Cook KF, Mathis KB. The John Insall Award: Patient expectations affect satisfaction with total knee arthroplasty. Clin Orthop Relat Res. 2006;452:35-43.
31. Nota SP, Spit SA, Oosterhoff TC, Hageman MG, Ring DC, Vranceanu AM. Is social support associated with upper extremity disability? Clin Orthop Relat Res. 2016;474:1830-1836.

32. Ragab AA. Validity of self-assessment outcome questionnaires: patient-physician discrepancy in outcome interpretation. Biomed Sci Instrum. 2003;39:579-584.

33. Rogers F, Horst M, To T, Rogers A, Edavettal M, Wu D, Anderson J, Lee J, Osler T, Brosey L. Factors associated with patient satisfaction scores for physician care in trauma patients. $J$ Trauma Acute Care Surg. 2013;75:110-114; discussion 114-115.

34. Rohrich RJ. Mirror, mirror on the wall: when the postoperative reflection does not meet patients' expectations. Plast Reconstr Surg. 2001;108:507-509.

35. Scott CE, Bugler KE, Clement ND, Macdonald D, Howie CR, Biant LC. Patient expectations of arthroplasty of the hip and knee. J Bone Joint Surg Br. 2012;94:974-981.

36. Strauss A, Corbin J. Basics of Qualitative Research: Techniques and Procedures for Developing Grounded Theory. 2nd ed. Thousand Oaks, CA: Sage Publications; 1998.

37. Wolf JM, Delaronde S. Current trends in nonoperative and operative treatment of trapeziometacarpal osteoarthritis: a survey of US hand surgeons. $J$ Hand Surg Am. 2012;37:77-82.

38. Wright JG, Young NL. The patient-specific index: asking patients what they want. J Bone Joint Surg Am. 1997;79:974-983.

39. Van Heest AE, Kallemeier P. Thumb carpal metacarpal arthritis. J Am Acad Orthop Surg. 2008;16:140-151.

40. Vranceanu AM, Barsky A, Ring D. Psychosocial aspects of disabling musculoskeletal pain. $J$ Bone Joint Surg Am. 2009;91:2014-2018.

41. Vranceanu AM, Jupiter JB, Mudgal CS, Ring D. Predictors of pain intensity and disability after minor hand surgery. $J$ Hand Surg Am. 2010;35:956-960.

42. Vranceanu AM, Ring D. Factors associated with patient satisfaction. J Hand Surg Am. 2011;36:1504-1508.

43. Zywiel MG, Mahomed A, Gandhi R, Perruccio AV, Mahomed NN. Measuring expectations in orthopaedic surgery: a systematic review Clin Orthop Relat Res. 2013;471:3446-3456. 